\title{
Importancia del recuento de la densidad celular endotelial en el tejido corneal con fines de trasplante en el Banco de Ojos del Hospital General de Cholula
}

\author{
Importance of endothelial cell density count in corneal tissue \\ for transplant in the Eye Bank of the General Hospital of Cholula
}

\author{
Marla Patricia León-Domínguez,* Marcela Tejeda-Mondragón, ${ }^{*}$ \\ Denhi Benn Monter-Valera, ${ }^{\S}$ Martha Elena Barrientos-Núñez ${ }^{\|}$ \\ * Médico Pasante de Servicio Social, Universidad de las Américas Puebla, Unidad de Trasplantes Puebla. \\ ‡ Cirujana Oftamóloga, Responsable del Banco de Ojos, Servicio de Oftalmología, Hospital General de Cholula. \\ $\S$ Jefa de Enseñanza, Hospital General de Cholula. \\ "Responsable de la Unidad de Trasplantes Puebla.
}

\section{RESUMEN}

Introducción: Demostrar la importancia del recuento de la densidad celular endotelial por medio de microscopia especular, como un factor importante e independiente de los rangos de edad del donante de tejido corneal. Material y métodos: Es un estudio transversal, observacional, descriptivo, retrospectivo y prospectivo donde se analizaron 98 córneas, de las cuales siete se eliminaron por lectura ilegible, con una muestra final de 91 córneas. Éstas fueron donadas para fines de trasplante en el estado de Puebla y analizadas por el Banco de Tejido Ocular del Hospital General de Cholula de junio 2019 a enero 2020. Para fines del estudio, las córneas se dividieron por grupos de edad por década. Resultados: De las 91 córneas analizadas, se observó un mayor número de donaciones en la década 7, con 22 córneas. Se encontró respecto a la densidad celular una media de 1,976 $\pm 613.45 \mathrm{cél} / \mathrm{mm}^{2}$, siendo la mínima de 554 cél $/ \mathrm{mm}^{2}$ en una córnea de 38 años y la máxima de 3,484 cél $/ \mathrm{mm}^{2}$ en una córnea de 17 años, el coeficiente de variación presentó una media de $58.48 \pm 20.519$, una mínima de 38 en una córnea de 62 años y la máxima de 216 en una córnea de 49 años y respecto a la hexagonalidad con una media de 42.68 $\pm 8.31 \%$, con una mínima de $7 \%$ en una córnea de 73 años y máxima de $61 \%$ en una córnea de 17 años. Se obtuvo un valor p estadísticamente significativo de $<0.001$ en el estudio de

\begin{abstract}
Introduction: Demonstrate the importance of count the endothelial cell density by specular microscopy, as an important factor independent of the age ranges of the donor of corneal tissue. Material and methods: This is a crosssectional, observational, descriptive, retrospective and prospective study. 98 corneas were analyzed, of which seven were removed by illegible reading, with a final sample of 91 corneas. These were donated for transplant purposes in the state of Puebla and analyzed by the Ocular Tissue Bank of the General Hospital of Cholula from June 2019 to January 2020. For study purposes, the corneas were divided by age groups by decade. Results: Of the 91 corneas analyzed, a greater number of donations was observed in decade 7, with 22 corneas. Regarding cell density, an average of 1,976 \pm 613.45 cells $/ \mathrm{mm}^{2}$ was found, the minimum being 554 cells $/ \mathrm{mm}^{2}$ in a 38-year-old cornea and the maximum being 3,484 cells $/ \mathrm{mm}^{2}$ in a 17-year-old cornea, the coefficient of variation presented an average of $58.48 \pm 20,519$, a minimum of 38 in a 62-yearold cornea and a maximum of 216 in a 49-year-old cornea and with respect to hexagonality with an average of $42.68 \pm 8.31 \%$, with a minimum of $7 \%$ in a cornea of 73 years and a maximum of $61 \%$ in a cornea of 17 years. A statistically significant $p$ value of $<0.001$ was obtained in the study of cell density
\end{abstract}


la densidad celular y de $<0.039$ de hexagonalidad. Conclusiones: Se demostró la utilidad e importancia de evaluar el tejido corneal, independientemente de la edad del donador con microscopia especular. Se demostró que la densidad celular sí presenta una disminución lineal por década de edad; sin embargo, cuenta con una variable significativa, un dato representativo es la córnea de menor celularidad de todo el estudio, la cual es de 38 años con 554 cél $/ \mathrm{mm}^{2}$, así mostrando que la edad no es un parámetro fiable para evaluar la calidad de una córnea. La córnea más joven del estudio fue de 15 años, con una densidad celular de $2,222 \mathrm{cél} / \mathrm{mm}^{2}$ y fueron dos córneas de mayor edad con 78 años con una densidad de 1,241 cél $/ \mathrm{mm}^{2}$ y 1,410 cél $/ \mathrm{mm}^{2}$. La hexagonalidad mostró una disminución por década, datos que se relacionan con lo descrito en la literatura, aunque el coeficiente de variación no mostró relación estadística con la edad. Se debe mencionar que el $78 \%$ de la población estudiada presentó pleomorfismo y $87.9 \%$ presentó polimegatismo.

Palabras clave: Miscroscopia especular, coeficiente de variación, densidad celular, banco de ojos, trasplante de córnea.

\section{INTRODUCCIÓN}

La córnea es un tejido avascular con una forma oval, cuenta con una zona de transición en la periferia donde se transforma en esclera, cuenta con un diámetro de $11.7 \times 10.6 \mathrm{~mm}$, un espesor central de 535 micras, contenido de agua $78 \%$, contenido de colágeno 15 y $5 \%$ de otras proteínas, con un poder refractivo total de 43.05 dioptrías. Cuenta con cinco capas, desde su superficie anterior empieza con el epitelio, la membrana de Bowman, estroma, membrana de Descemet y el endotelio. Entre sus funciones está el permitir la transmisión de la luz y con la refracción ayuda a la focalización en el fondo de ojo, al igual que a proteger las estructuras intraoculares. El endotelio es una capa única de células escamosas de forma hexagonal, estas células no se reproducen después del nacimiento, por lo que no puede regenerarse en el endotelio.

Se ha documentado que hay una pérdida de la densidad endotelial conforme aumenta la edad y cuando una célula endotelial muere, las células vecinas ocupan el espacio vacío y así modifican su tamaño, lo cual se conoce como polimegatismo y modifican su forma, conocido como pleomorfismo. Para mantener la transparencia corneal, se necesita de un número mínimo de células endoteliales de 700 a 1,000 cél $/ \mathrm{mm}^{2}$. Al nacimiento, el humano tiene entre 2,987 y 5,632 cél $/ \mathrm{mm}^{2}$, este número va disminuyendo con el paso de los años, en un estudio del endotelio corneal en pacientes sin patología ocular por Martínez de la Casa JM en 2004 se menciona que entre los 20-30 años de edad existen en- and $<0.039$ of hexagonality. Conclusions: The utility and importance of evaluating corneal tissue was demonstrated, regardless of donor age with specular microscopy. It was shown that cell density does show a linear decrease per decade of age, however it has a significant variable, a representative figure is the cornea with the least cellularity in the entire study, which is 38 years old with 554 cells $/ \mathrm{mm}^{2}$, thus showing that age is not a reliable parameter to evaluate the quality of a cornea. The youngest cornea in the study was 15 years old, with a cell density of 2,222 cells $/ \mathrm{mm}^{2}$, and two older corneas were 78 years old with a density of $1,241 \mathrm{cells} / \mathrm{mm}^{2}$ and $1,410 \mathrm{cells} / \mathrm{mm}^{2}$. The hexagonality showed a decrease per decade, data that is related to that described in the literature, however the coefficient of variation did not show a statistical relationship with age. It should be mentioned that $78 \%$ of the studied population presented pleomorphism and $87.9 \%$ presented polymegatism.

Keywords: Specular microscopy, coefficient of variation, cell density, eye bank, cornea transplant.

tre 3,000 y $3,500 \mathrm{cél} / \mathrm{mm}^{2}$, a los $40-50$ años entre 2,500 y $3,000 \mathrm{cél} / \mathrm{mm}^{2}$ y en mayores de 80 años entre 2,000 y $2,500 \mathrm{cé} / / \mathrm{mm}^{2} .{ }^{1}$ Para conocer las características endoteliales de la córnea, su análisis se puede hacer por medio de dos métodos, con una lámpara de hendidura o por microscopia especular, pero por medio de esta última se puede estudiar la córnea y sus diferentes capas con una magnificación mayor de 100 veces que por medio de la biomicroscopia con lámpara de hendidura. Al analizar, la imagen del tejido corneal se podrá obtener información respecto al tamaño, su forma, densidad y la distribución que presentan las células. ${ }^{2}$

La ceguera representa una incapacidad para la población afectada, por lo que el tratamiento con trasplante de córnea es de suma importancia. La queratoplastia penetrante está indicada en casos de queratocono, ectasias corneales, queratopatía bulosa quirúrgica, distrofia endotelial, traumatismo, quemaduras, queratitis herpética, etcétera. Los Bancos de Ojos tienen como objetivo la obtención, evaluación y distribución del tejido corneal. En México, se estableció el primer Banco de Ojos en 1975 en el Hospital de Coyoacán en la Ciudad de México. ${ }^{3}$ El proceso de donación y trasplante de córneas es un proceso relativamente rápido si se compara con la procuración de los órganos, éste debe seguir ciertos protocolos; en España, una vez extraído el tejido, debe ser analizado bajo una lámpara de hendidura y en todo caso que se tenga acceso realizar un recuento endotelial. La edad puede ser considerada un factor de riesgo, al igual que el proceso de extracción, durante la procuración puede existir hasta 
un $10 \%$ de pérdida del número de células endoteliales, por lo cual es de suma importancia realizar el análisis de las córneas por microscopia especular, en la cual se obtendrán datos sobre pleomorfismo celular, lo que incluye información sobre la hexagonalidad, el polimegatismo (coeficiente de variación en el tamaño celular) y la densidad celular, incluso observar la presencia de guttas. Los rangos considerados en España para trasplante son mínimo de 2,000 a 2,200 cél/ $\mathrm{mm}^{2}$ en las córneas analizadas por microscopia especular. ${ }^{4}$

En la guía de práctica clínica de «queratoplastia penetrante» publicada en el 2011 por el CENETEC, se hace mención del análisis del endotelio corneal por medio de microscopia especular para conocer la salud del endotelio corneal. La utilidad del botón donador dependerá de diversos factores, las características óptimas serán: aspecto transparente, superficie lisa y homogénea, con espesor y curvatura conservada, morfología celular hexagonal conservada, cuenta mínima de $2,500 \mathrm{~mm}^{2}$ células endoteliales (CD) que deberá especificar la presencia o ausencia de pleomorfismo, porcentaje de células hexagonales (HEX), coeficiente de variación $(\mathrm{CV})$, número de células pentagonales y heptagonales. Según datos presentados en la guía, la edad del donador estará relacionada con la sobrevida del botón corneal, los botones de 30 años o menos tendrán una sobrevida aproximada de $93 \%$ y mayores de 80 años pueden ofrecer una sobrevida de $85 \% .{ }^{5}$ En cambio, el comité parte de "The Cornea Donor Study Research Group» de Estados Unidos, en una publicación del año 2015, señala que los estudios realizados han demostrado que la edad no es un factor en la supervivencia del injerto en la queratoplastia penetrante para enfermedades endoteliales. Analizaron córneas que dividieron en dos grupos, de donadores de 12 a 65 años y de 66 a 75 años, compararon ambos grupos a los cinco años y no encontraron diferencia en la supervivencia del injerto. A los 10-12 años, se encontró una pequeña diferencia pero no significativa, con una supervivencia del $77 \%$ en el grupo más joven y del grupo mayor un $71 \%$. Aunque encontraron factores que influyen más que la edad para la supervivencia del injerto, como la densidad de las células endoteliales, con menos de $1,700 \mathrm{cél} / \mathrm{mm}^{2}$ y el grosor corneal menor a 600 $\mu \mathrm{m}$ al año postoperatorio fue asociado a un incremento de riesgo de falla del injerto a los cinco años. ${ }^{6}$

\section{Estudios previos}

Se han realizado diferentes estudios alrededor del mundo sobre las características del endotelio del tejido corneal en diferentes poblaciones. En Coahuila, México, se realizó un estudio en 2014 , donde hacen mención de investigaciones que han demostrado diferencia significativa entre la densidad de células endoteliales entre la población americana y japonesa; en dicho estudio reportaron que su valor promedio de densidad de células endoteliales fue de 2,632.03 \pm 272.19 cél/ $\mathrm{mm}^{2} .7$ Otro estudio presentado por la Universidad de Bergen y el Hospital Universitario Haukeland en Noruega evaluó la influencia de la edad de los donadores y la causa de muerte con la densidad endotelial, en el cual dividieron a las córneas donadas en tres grupos de edad, menores de 50 años de edad, de 51 a 75 años de edad y mayores de 75 años, y obtuvieron un promedio de densidad de células endoteliales para el primer grupo de 2,868 cél/ $/ \mathrm{mm}^{2}$, segundo grupo 2,716 cél $/ \mathrm{mm}^{2}$ y el tercer grupo $2,670 \mathrm{cél} / \mathrm{mm}^{2} .{ }^{8}$ Un estudio por Hochschule Aalen en la Universidad de Alemania, donde el objetivo era buscar si existe relación lineal de la pérdida de densidad celular de tejido endotelial con la edad, en sus resultados presentan que al nacimiento la densidad celular es de $2,957 \mathrm{cé} / \mathrm{mm} \mathrm{mm}^{2}$ y se calcula una pérdida anual de $7.58 \mathrm{cél} / \mathrm{mm}^{2}$, con la edad el polimegatismo aumenta y el número de células hexagonales disminuye, desde el nacimiento hasta los 35 años de edad la pérdida de densidad celular es continua, después de esta edad la pérdida se presenta con una tasa más baja. Sugieren que los cambios de la estructura del endotelio corneal son diferentes en las primeras tres décadas de la vida comparado con las décadas posteriores, así demostraron que la edad generalmente no es un factor decisivo para las cirugías intraoculares. Respecto al pleomorfismo según la edad, el número de células hexagonales al nacimiento es en promedio de $46.79 \%$ con una pérdida de $0.128 \%$ anual, en cuanto al coeficiente de variación, que se presenta como el aumento de la polimegatividad (el cambio en el tamaño de células endoteliales), se relacionó en función a la edad, al nacimiento un $35.758 \%$, en su población estudiada con una media de 38.80 $\pm 6.55 \%$ y con una pérdida de 0.0743 por año. ${ }^{9}$ En el Hospital de Oftalmología Fundación Conde Valencia, publicaron una investigación en 2005 que evaluó el comportamiento de las células endoteliales corneales por décadas de edad, donde mostraron que estadísticamente la pérdida celular es mayor en la edad entre 20-29 años, con una pérdida celular anual de $0.46 \%$ en promedio, comparando los grupos de edad por década, presentaron una pérdida de $11.5 \%$, que aumentó con el grupo de 50-59 años a una pérdida de $21.2 \%$. Con un máximo de pérdida de células endote- 
liales de $44.1 \%$ y en pacientes mayores de 60 años de edad. Respecto al coeficiente de variación, no encontraron cambios significativos en ningún grupo de edad, el aumento más importante fue de $5.63 \%$ en el grupo de 20 a 29 años. En la hexagonalidad, los resultados significativos fueron a partir del grupo de 20 a 29 años de edad, con una disminución de $14.47 \%$, con un promedio de pérdida anual de $0.22 \% .^{10}$

\section{Donación de tejido corneal}

La donación de tejidos de donante cadavérico incluye el tejido corneal. Según los últimos datos publicados por el Centro Nacional de Trasplantes en el reporte anual 2019 de donación y trasplantes, en México existen 5,713 receptores en lista de espera para córnea. En el año 2018 se realizaron 4,347 trasplantes en todo el país, con una disminución en el año 2019 con 3,766 trasplantes en el país, a pesar de que existe un número importante de trasplantes anuales aún no es suficiente para la demanda de receptores en lista de espera. ${ }^{11}$ Existen criterios establecidos para la donación de tejido corneal, aunque no hay suficiente evidencia científica que señale a la edad como un factor determinante para la viabilidad de un tejido corneal, algunos bancos delimitan la edad y de esta manera el número de donaciones se ve afectado. La manera adecuada para evaluar la calidad del tejido corneal no es el parámetro de la edad, sino la evaluación por medio de microscopia especular. En Estados Unidos de América, aproximadamente el $50 \%$ de los donantes de tejido corneal son mayores de 60 años de edad, donde existe el debate si debe existir una edad límite para ser donante de tejido corneal, incluso existen bancos de ojos que establecen como límite de edad los 65 años, sin tener evidencia científica que respalde esta limitante, ya que no existen estudios que establezcan que la edad pueda ser un factor único de éxito para el trasplante de córnea. ${ }^{5}$

Durante la queratoplastia penetrante existe una pérdida celular endotelial del $15.93 \%$, según estudios que compararon la densidad celular reportada por un banco de ojos en el análisis del botón corneal previo al trasplante y en el postoperatorio de los receptores a los 15 y 30 días, donde no encontraron relación de la disminución de las células con la edad, excepto en pacientes de 25 a 49 años de edad, encontraron relación con la colocación, toma y tiempo de preservación del injerto, presentando un menor conteo celular entre mayor fuera el tiempo de colocación del botón corneal. ${ }^{12}$

\section{Cuidados oculares}

La donación de córnea es posible en donación por muerte por parada cardiaca y por muerte encefálica, ya que es un tejido. Los potenciales donadores generalmente se encuentran en estado crítico y tienen el riesgo de sufrir una queratitis por exposición, ésta es una de las alteraciones que presentan con mayor frecuencia los pacientes hospitalizados. Su presentación depende de diversos factores, principalmente por exposición ocular que puede presentarse por el lagoftalmos en los pacientes. Esta es una complicación prevenible, por lo que es importante vigilar y realizar cuidados corneales a los pacientes hospitalizados especialmente en estado crítico, ya que si recuperan su estado de salud, su función visual podría estar afectada y en caso de fallecimiento como potencial donante la córnea podría perder calidad, ya que la queratitis lleva a la pérdida de la trasparencia corneal e incluso se puede dañar el tejido y perderse. Un estudio publicado por el Centro Médico Nacional del Occidente en Jalisco reportó una prevalencia de queratitis por exposición en pacientes hospitalizados en la UTI de $12.5 \%$, el cual fue un rango inferior a lo reportado en la literatura, donde reportan desde 3.6 hasta $60 \%$ de prevalencia. Cabe mencionar que la importancia de su prevalencia más baja radica en que durante su estudio realizaron cuidados oculares en los pacientes estudiados y se detectaron las lesiones en un tiempo promedio de 8.9 días de hospitalización. ${ }^{13}$

Los cuidados oculares se recomiendan en los potenciales donantes para evitar daños en la superficie corneal, el manejo que se dará será de acuerdo con el grado de cierre palpebral y el lagoftalmos, se divide en tres grados: grado 0 párpado cerrado, grado 1 conjuntiva expuesta y grado 2 córnea expuesta. Para el grado 0 requiere lubricación cada cuatro a seis horas y valoración diaria de cierre palpebral, en grado 1 se requiere lubricación cada dos a cuatro horas, tapar con cinta adhesiva, valoración diaria de cierre palpebral e interconsulta con oftalmología para valoración y en grado 2 se requiere lubricación cada una a dos horas, cámara húmeda permanente, valoración diaria de cierre palpebral y valoración por oftalmólogo. Es importante dar seguimiento a los pacientes hospitalizados en UTI y detectar cualquier complicación a tiempo para evitar secuelas y tratarlas adecuadamente. ${ }^{14}$

\section{MATERIAL Y MÉTODOS}

Se realizó un estudio transversal, observacional, descriptivo, retrospectivo y prospectivo. Se evaluaron un to- 


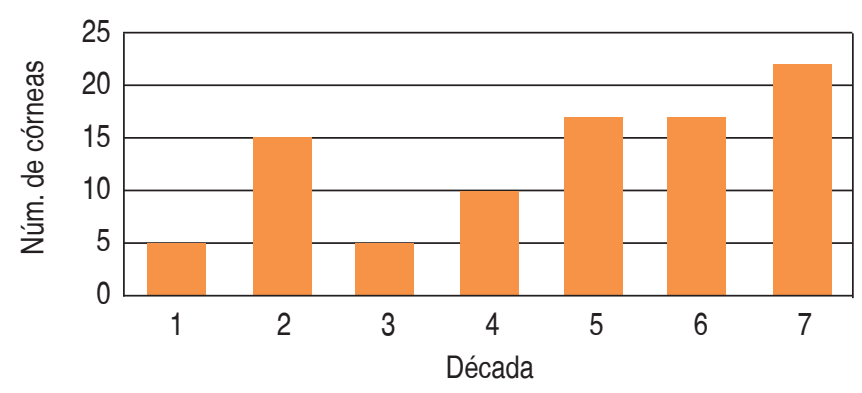

Figura 1: Total de córneas analizadas por década, presentando el mayor número de córneas analizadas en el estudio la década 7 con 22 córneas, y el menor número en la década 1 y 3.

tal de 98 córneas, las cuales fueron donadas con fines de trasplante en el estado de Puebla y analizadas por el Banco de Ojos del Hospital General de Cholula en el periodo de junio 2019 a enero 2020. La investigación comenzó en septiembre 2019. De las 98 córneas, siete fueron eliminadas al obtener una lectura ilegible, por lo que la muestra para este estudio fue de 91 córneas, de las cuales 47 fueron de hombres y 44 de mujeres.

Los criterios de inclusión que se tomaron fueron córneas de donadores a partir de los dos años de edad sin límite de edad máxima, tejido corneal de donadores que fueran analizados por el Banco de Ojos del Hospital General de Cholula del estado de Puebla, como criterios de exclusión se condicionó tejido corneal que no contara con los datos de edad y sexo del donador, y como criterio de eliminación el tejido corneal con lectura ilegible.

Para fines del estudio, las 91 córneas se dividieron por grupo de edad por décadas, partiendo de la década 1 (10-19 años), década 2 (20-29 años), década 3 (30-39 años), década 4 (40-49 años), década 5 (50-59 años), década 6 (60-69 años) y la década 7 (70-79 años). El análisis microscópico de las córneas se hizo con el equipo de Konan CéllChek D+ Microscopio especular para Banco de Ojos, para obtener los parámetros estudiados de densidad celular (CD), coeficiente de variación (CV) y hexagonalidad (HEX), relacionando el análisis de la calidad del tejido corneal por microscopia con la edad de los pacientes donadores por década. El análisis estadístico se hizo con el programa Minitab.

El estudio fue autorizado por el Comité de Bioética y Comité de Ética en Investigación del Hospital General de Cholula.

\section{RESULTADOS}

El total de la muestra inicial fue de 98 córneas donadas, por criterios de eliminación la población final fue de 91 córneas, representando el $92.8 \%$ de la población inicial, las cuales presentaron la siguiente distribución por décadas siendo la séptima la de mayor número de córneas donadas con 22 (Figura 1), sin diferencia de género. La córnea con menor edad fue de un donador de 15 años y las de mayor edad fueron dos córneas de 78 años.

En el análisis por décadas (Tabla 1) se observan las diferencias en los grupos de edad de las variables estudiadas.

En el análisis general de la densidad celular, el coeficiente de variación y la hexagonalidad relacionados con las 7 décadas de la vida, se encontró que la población cuenta con una media de densidad celular de 1,976 $\pm 613.45 \mathrm{cé} / / \mathrm{mm}^{2}$, siendo la mínima de $554 \mathrm{cél} / \mathrm{mm}^{2}$ en una córnea de 38 años, la cual presenta pleomorfimo y polimegatismo (Figura 2) y la máxima de 3,484 cél $/ \mathrm{mm}^{2}$ en una córnea de 17 años (Figura 3). El coeficiente de variación presentó una media de $58.48 \pm 20.519$, una mínima de 38 en una córnea de 62 años y la máxima de 216 en una córnea de 49 años y respecto a la hexagonalidad una media de $42.68 \pm 8.3 \%$, una mínima de $7 \%$ en una córnea de 73 años y máxima de $61 \%$ en una córnea de 17 años. Se obtuvo un valor $p$ estadísticamente significativo de $<0.001$ en el estudio de la densidad celular y de $<0.039$ de hexagonalidad, en cambio el coeficiente de variación no demostró un valor estadístico significativo.

Respecto a la densidad celular (CD) (Figura 4) comparando la córnea con mayor y menor CD por década, se encontró que en la década 1 la córnea con mayor CD fue de 17 años con 3,356 cél $/ \mathrm{mm}^{2}$ y la de menor CD fue de 2,222 cél/ $\mathrm{mm}^{2}$, en la década 2 la córnea con mayor CD fue de $2,865 \mathrm{cél} / \mathrm{mm}^{2}$ con 28 años y la córnea con menor fue de 22 años con 1,887 cél $/ \mathrm{mm}^{2}$, en la década 3 la córnea con mayor CD fue

Tabla 1: Análisis por década de media de densidad celular, media de coeficiente de variación y media de hexagonalidad.

\begin{tabular}{cccc}
\hline Década (años) & CD cél/mm² & CV & HEX \% \\
\hline 1 (10-19) & 2,952 & 50.00 & 48.4 \\
$2(20-29)$ & 2,389 & 53.00 & 45.6 \\
$3(30-39)$ & 2,051 & 59.00 & 43.8 \\
$4(40-49)$ & 1,914 & 76.30 & 38.2 \\
$5(50-59)$ & 1,959 & 55.35 & 43.5 \\
$6(60-69)$ & 1,854 & 56.82 & 42.8 \\
$7(70-79)$ & 1,554 & 59.63 & 40.2 \\
\hline
\end{tabular}

Media por grupo de edad. 


\begin{tabular}{lcc}
\multicolumn{3}{c}{ Promedio multi-muestra } \\
\hline $\mathrm{CD}$ & cél/mm² & 3,484 \\
$\mathrm{CV}$ & & 41 \\
$\mathrm{HEX}$ & $\%$ & 56 \\
$\mathrm{DE}$ & & 119 \\
Total área & $\mu \mathrm{m}^{2}$ & 82,699 \\
Total número & & 288 \\
\hline
\end{tabular}

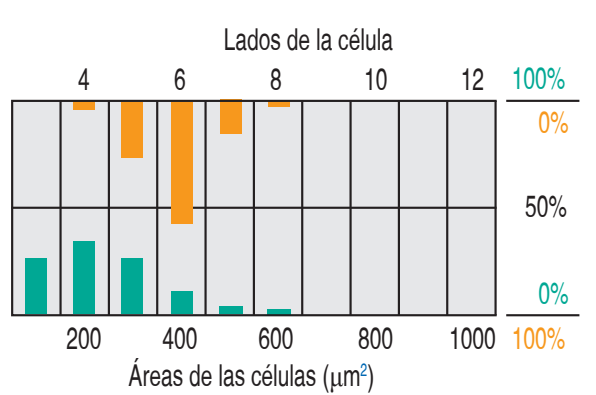

\begin{tabular}{|c|c|c|c|c|}
\hline 3,484 & cél/mm² & $C D$ & cél//mm² & - \\
\hline 41 & & CV & & - \\
\hline 56 & $\%$ & HEX & $\%$ & - \\
\hline 119 & & DE & & - \\
\hline 287 & $\mu \mathrm{m}^{2}$ & Ave & $\mu \mathrm{m}^{2}$ & - \\
\hline 288 & & Número & & - \\
\hline- & cél/mm² & $C D$ & cél $/ \mathrm{mm}^{2}$ & - \\
\hline - & & CV & & - \\
\hline- & $\%$ & HEX & $\%$ & - \\
\hline- & & $\mathrm{DE}$ & & - \\
\hline- & $\mu \mathrm{m}^{2}$ & Ave & $\mu \mathrm{m}^{2}$ & - \\
\hline- & & Número & & - \\
\hline
\end{tabular}

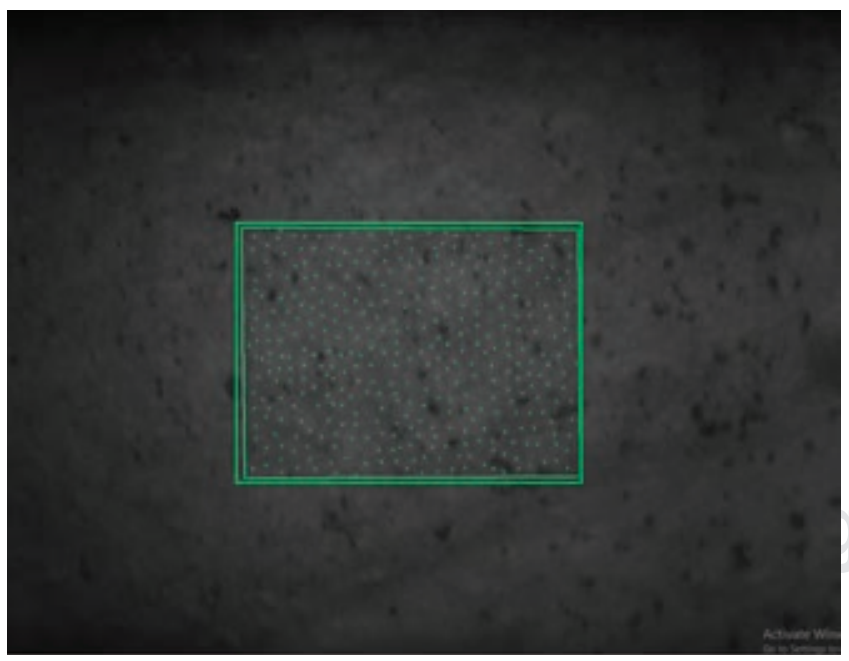

Figura 2: Análisis por microscopia especular de córnea derecha de donador de 17 años de edad, siendo la córnea con mayor densidad celular del estudio, con 3,484 cél/ $\mathrm{mm}^{2}$, no presentó pleomorfismo o polimegatismo. Fotografía del Banco de Ojos del Hospital General de Cholula. de 33 años con 3,067 cél $/ \mathrm{mm}^{2}$ y la de menor de 38 años con 554 cél $/ \mathrm{mm}^{2}$; la córnea con menor CD de todo el estudio estuvo en la década 4, la córnea con mayor CD fue de 40 años con $2,506 \mathrm{cél} / \mathrm{mm}^{2}$ y la de menor de 49 años con $1,116 \mathrm{cé} / \mathrm{mm}^{2}$, en la década 5 la córnea con mayor CD fue de 58 años con 2,825 cél $/ \mathrm{mm}^{2}$ y la córnea con menor fue de 59 años con $1,344 \mathrm{cé} / \mathrm{mm}^{2}$, en la década 6 la córnea con mayor CD fue de 58 años con $2,825 \mathrm{cél} / \mathrm{mm}^{2}$ y la córnea con menor fue de 59 años con 1,344 cél/ $\mathrm{mm}^{2}$ y en la década 7 la córnea con mayor CD fue de 70 años con 2,336 cél/ $\mathrm{mm}^{2}$ y la córnea con menor fue de 73 años con $693 \mathrm{cé} / \mathrm{mm}$.

Tomando como criterio 2,000 cél/mm² como mínimo de densidad celular para un trasplante, en la década 1 el $100 \%$ de las córneas cumplen con el criterio, en la década 2 el $86 \%$, década 3 y 4 el $60 \%$, década 5 el $47 \%$, década 6 el $35 \%$ y en la década 7 un $27 \%$, con lo que se observa un comportamiento descendente de la calidad por década.

En el caso del coeficiente de variación (Figura 5), en la década 1 se encontró el valor mínimo de 38 en una córnea de 17 años y el valor mayor de 63 en una córnea de 15 años, en la década 2 se encontró un valor mínimo de 47 en córneas de 26 años y el valor mayor de 73 en una córnea de 22 años, en la década 3 el valor mínimo fue de 45 en una córnea de 38 años y el valor mayor de 85 en una córnea de 35 años, en la década 4 el valor mínimo fue de 50 en una córnea de 49 años y el valor mayor de 216 en una córnea de 49 años, siendo la córnea con mayor coeficiente de variación del estudio, en la década 5 el valor mínimo fue de 43 en una córnea de 52 años y el valor mayor de 76 en una córnea de 59 años, en la década 6 el valor mínimo fue de 38 en una córnea de 62 años y el valor mayor fue de 75 en una córnea de 67 años y una córnea de 63 años, en la década 7 el valor mínimo fue de 44 en una córnea de 73 años y el valor mayor fue de 88 en una córnea de 71 años.

La hexagonalidad (Figura 6) mostró en la década 1 la córnea con mayor porcentaje con $61 \%$ en una córnea de 17 años, con el valor mínimo de 38\% en una córnea de 15 años, en la década 2 el número mayor fue de $54 \%$ en una córnea de 29 años y el valor mínimo fue de $25 \%$ en una córnea de 22 años, en la década 3 el valor mayor fue de $49 \%$ en una córnea de 38 años y en valor mínimo de $40 \%$ en una córnea de 39 años, en la década 4 el valor mayor fue de $51 \%$ en una córnea de 46 años y un valor mínimo de $23 \%$ en una córnea de 48 años, en la década 5 el valor mayor fue de $52 \%$ en una córnea de 58 años y el valor mínimo de 
$28 \%$ en una córnea de 59 años, en la década 6 el valor mayor fue de $55 \%$ en una córnea de 63 años y el valor mínimo $31 \%$ en una córnea de 64 años y en la década 7 el valor mayor fue de $53 \%$ en 3 córneas, dos de 73 años y una de 78 años.

De acuerdo con los datos obtenidos por década de vida, existe en promedio una pérdida del $10 \%$ de densidad celular, un aumento del $4 \%$ del coeficiente de variación y la hexagonalidad disminuye un $3 \%$ en pro-
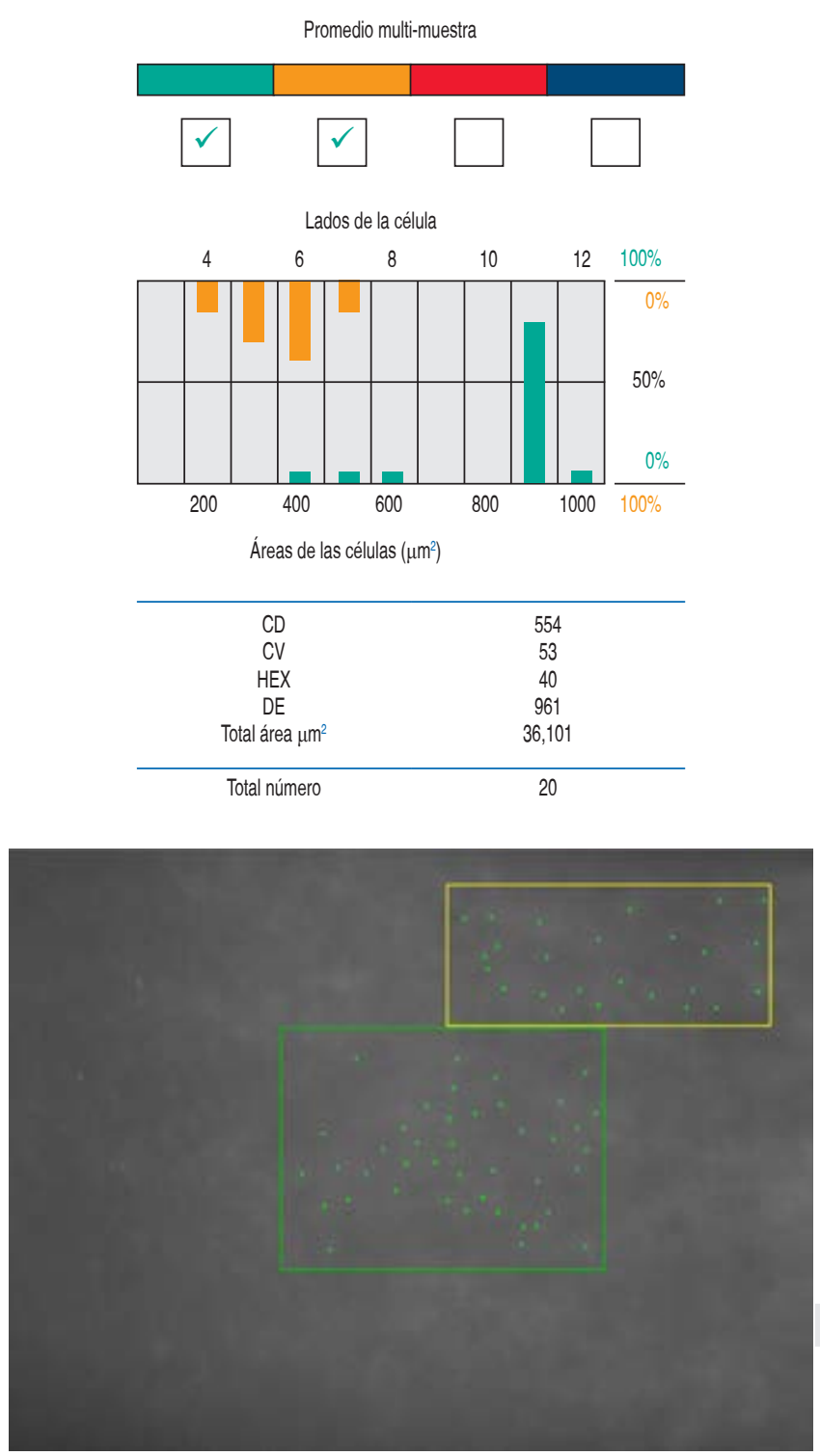

Figura 3: Análisis por microscopia especular de córnea derecha de donador de 38 años de edad, siendo la córnea con menor densidad celular del estudio con 554 cél/ $/ \mathrm{mm}^{2}$, esta córnea presenta pleomorfismo y polimegatismo. Fotografía del Banco de Ojos del Hospital General de Cholula. medio por década de vida, se debe destacar que los resultados estadísticamente significativos son los de densidad celular y hexagonalidad, estos demostraron una relación estadística con las décadas.

De la población analizada, el $78 \%$ presentó pleomorfismo (el porcentaje de células hexagonales debe ser $>50 \%$ para ser considerado normal) y $87.9 \%$ presentó polimegatismo (coeficiente de variación en tamaño celular mayor a $40 \%){ }^{15}$

\section{DISCUSIÓN}

En México, desde el primer trasplante de córnea que se realizó en 1966 gracias al trabajo del CENATRA, de los coordinadores hospitalarios y de las familias donadoras por todo el país, se ha logrado que este número haya aumentado hasta 4,353 trasplantes en el año 2018, con una disminución en el año 2019 con 3,766 trasplantes, los cuales en mayor porcentaje se realizaron en institución privada. A pesar de que el programa de donación y trasplante se ha expandido a lo largo del país, aún falta mucho para lograr satisfacer la lista de pacientes mexicanos en espera de un trasplante; para lograrlo, se necesita del trabajo de los coordinadores hospitalarios y, sobre todo, de la aceptación por parte de las familias mexicanas para la donación de órganos y tejidos con fines de trasplantes. El Banco de Ojos del Hospital General de Cholula, donde se llevó a cabo esta investigación, es el primer Banco de Ojos y actualmente el único del estado de Puebla donde se espera que todas las córneas que sean procuradas y trasplantadas puedan ser analizadas por el banco para ofrecer mayor seguridad para los receptores, ya que como se ha demostrado en los diversos estudios mencionados, la supervivencia del injerto está relacionada con la densidad celular del botón corneal y no con la edad del donador. En España, las recomendaciones de la Organización Nacional de Trasplantes (ONT), de forma orientativa toman como criterio mínimo para que un botón corneal sea viable para trasplante una densidad celular de 2,000 $\mathrm{cél} / \mathrm{mm}^{2}$ para queratoplastia penetrante y para trasplante lamelar endotelial se toma un mínimo de $2,500 \mathrm{cél} / \mathrm{mm}^{2},{ }^{16}$ si tomamos el rango de 2,000 cél/ $\mathrm{mm}^{2}$ como criterio, en nuestra población donadora sólo el 51.64\% presentó el criterio mínimo para trasplante, es importante mencionar que este criterio se establece por cada Banco de Tejidos y por cada equipo de trasplante para decidir la viabilidad del botón corneal, por lo que fue posible trasplan- 


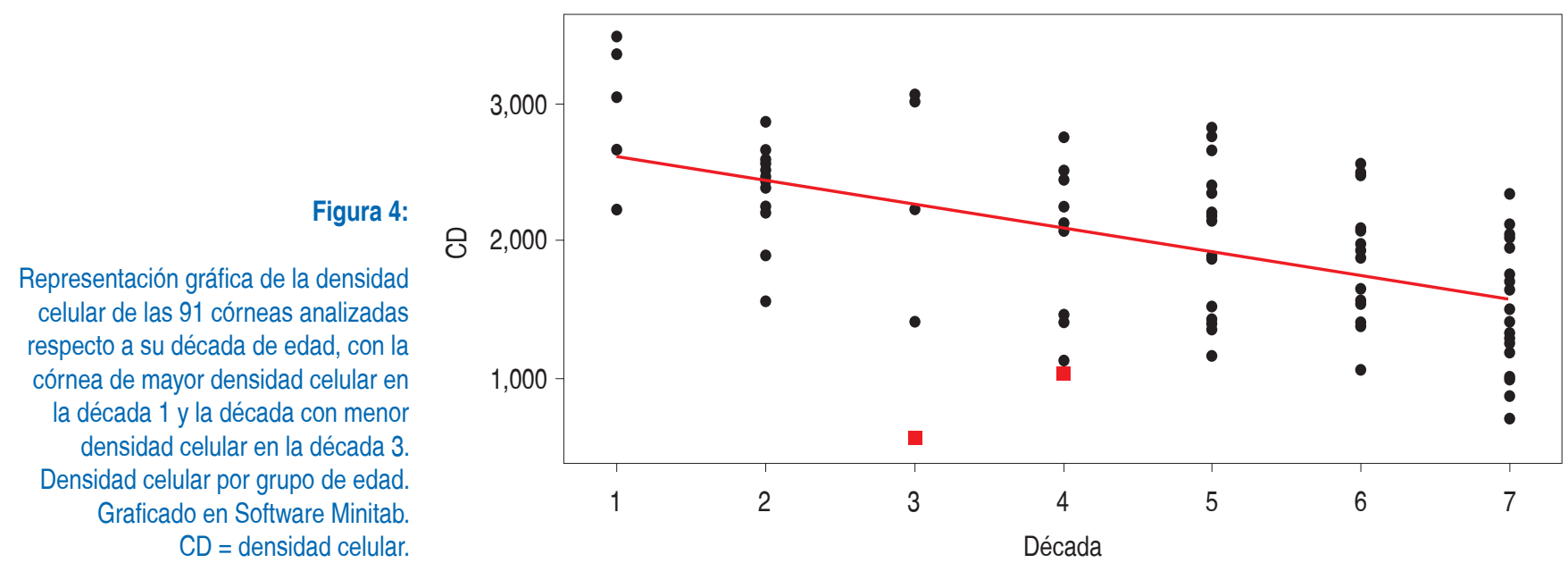

tar el $92 \%$ de las córneas analizadas por el Banco de Ojos, el cual hace una evaluación completa que incluye inspección macroscópica, evaluación bajo lámpara de hendidura, evaluación bajo el microscopio especular y cultivo del medio de preservación.

En el país existen diversos estudios publicados sobre la densidad celular, el coeficiente de variación y la hexagonalidad. En un estudio publicado en Coahuila por Rocío Guadalupe Contreras y colaboradores en el 2014, donde se estudiaron 60 ojos de jóvenes sanos vivos, obtuvieron un valor promedio de CD de 2,632.03 $\pm 272.19 \mathrm{cél} / \mathrm{mm}^{2}$, un CV de $42.55 \pm 9.23$. $^{7}$ En otra investigación publicada por Karla Verdiguel y su grupo de investigadores en el año 2016 en el Servicio de Oftalmología del Hospital General, Centro Médico Nacional «La Raza», analizaron 50 córneas, dividieron el estudio en dos grupos de acuerdo a quién procuró el tejido, el grupo 1 con médicos pasantes de servicio social y gru- po 2 con residentes del primer año de oftalmología, obtuvieron datos respectivamente de CD $2662.35 \pm$ 223.92 y $2656.44 \pm 156.14 \mathrm{cél} / \mathrm{mm}^{2} .{ }^{17}$ Una publicación cubana de Michel Guerra Almaguer y su equipo en el 2015 hace mención de diversos estudios, en los que evaluaron la densidad celular endotelial de distintas poblaciones del mundo, en Tailandia evaluaron un total de 404 ojos de pacientes sanos con un promedio de 2,623 cél $/ \mathrm{mm}^{2}$, en población de Perú presentaron 2,477 cél/ $/ \mathrm{mm}^{2}$, en China estudiaron 700 pacientes con un promedio de 2,932 cél/ $\mathrm{mm}^{2}$, en Estados Unidos con un promedio de 2,431 cél/ $\mathrm{mm}^{2}$, la población de Japón con 3,012 cél $/ \mathrm{mm}^{2}$ y la población de Irán presentó un promedio de 1,961 cél/ $\mathrm{mm}^{2}$, siendo la población iraní la que presentó mayor similitud respecto a la densidad celular a nuestra población estudiada en el estado de Puebla, aunque hay que tomar en cuenta que nuestra muestra es de donadores cadavéricos. ${ }^{15}$

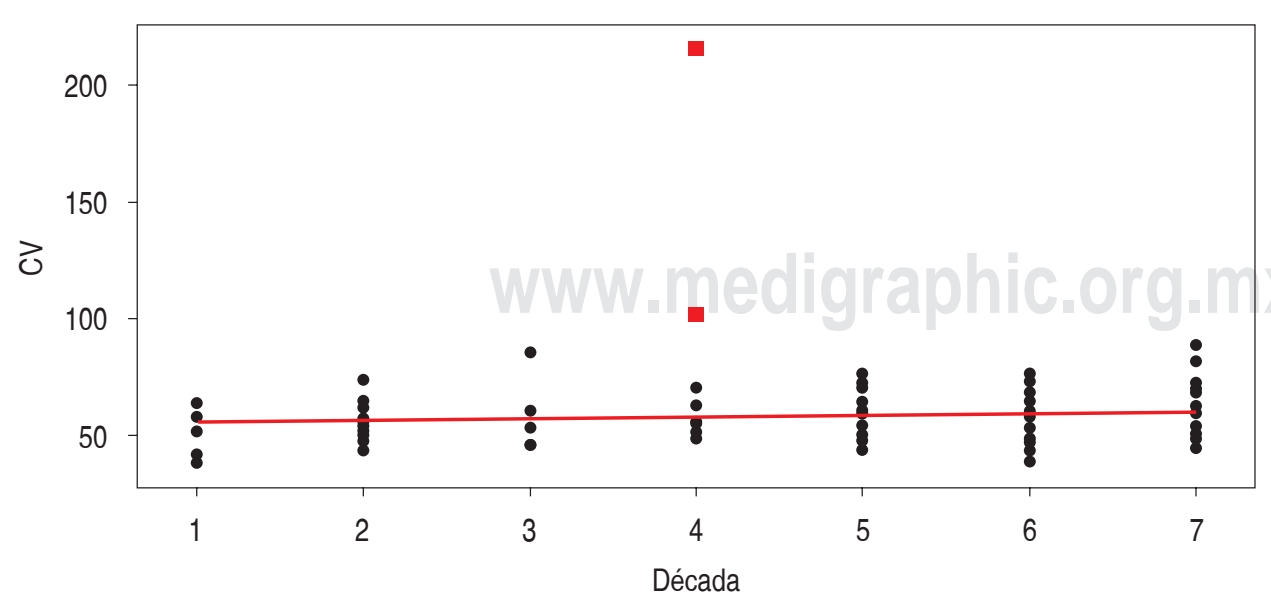

Figura 5:

Representación gráfica del coeficiente de variación de las 91 córneas analizadas respecto a su década de edad, con la córnea con mayor coeficiente de variación con 216 en la década 4 y el menor coeficiente de variación se presentó en dos córneas con 38 de coeficiente de variación de 62 años y de 17 años. Coeficiente de variación por grupo de edad Graficado en Software Minitab. $\mathrm{CV}=$ coeficiente de variación. 
Figura 6:

Representación gráfica de la hexagonalidad de las 91 córneas analizadas respecto a su década de edad, la córnea con mayor hexagonalidad fue de $61 \%$ de córnea de 17 años, y la córnea con menor hexagonalidad fue de $7 \%$ de una córnea de 73 años de edad. Hexagonalidad por grupo de edad Graficado en Software Minitab. HEX = hexagonalidad.

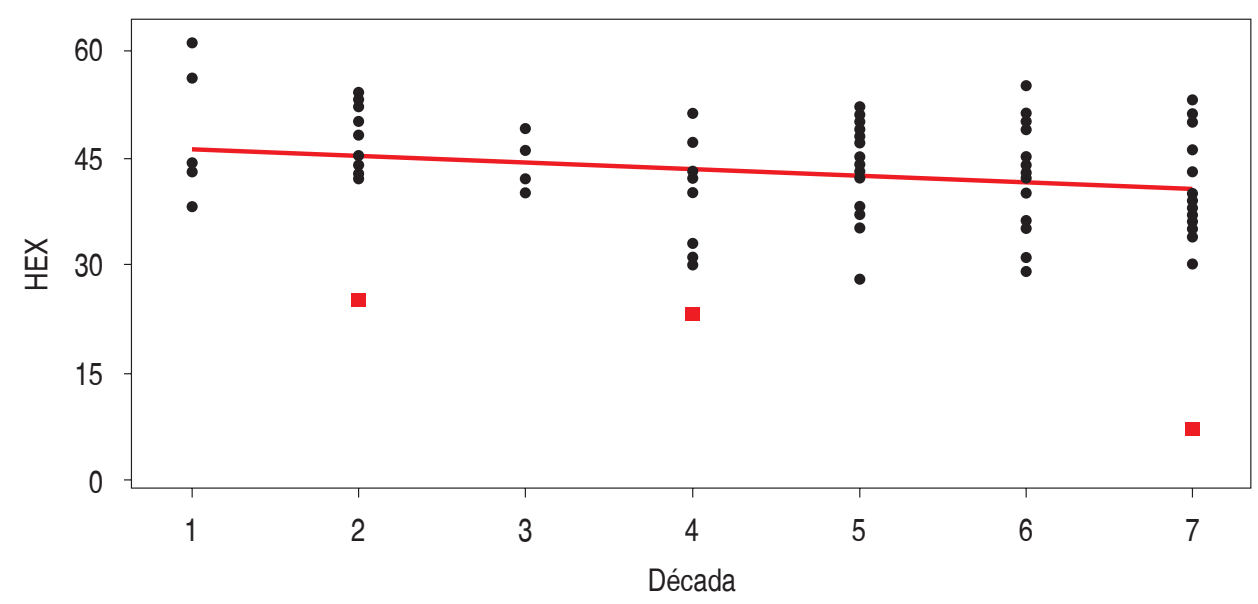

\section{CONCLUSIONES}

Se demostró la utilidad e importancia de evaluar por medio de microscopia especular el tejido corneal independientemente de la edad del donador, ya que se observó que la densidad celular presenta una disminución lineal por década de edad, datos similares a lo descrito en la literatura. Sin embargo, cuenta con una variable significativa, siendo la córnea con menor celularidad de 554 cél $/ \mathrm{mm}^{2}$ de 38 años, lo cual se podría considerar una córnea joven y mostrar que la edad no es un parámetro fiable para evaluar la calidad de una córnea. La hexagonalidad demostró que estadísticamente tiene una relación directa con la edad y disminuye a mayor década, el coeficiente de variación parece aumentar; sin embargo, no se encontró relación con la edad de manera estadística. Con los resultados obtenidos, se destaca la importancia de siempre realizar una evaluación del tejido corneal con microscopia especular, sin importar la edad del donador previo al trasplante, para así brindar mayor seguridad a los receptores tomando en cuenta que la literatura indica que la sobrevida del injerto tiene mayor relación con el número de células endoteliales que con la edad del donador.

\section{AGRADECIMIENTOS}

Al NPS. Xaman Rivas Zamudio por su valiosísimo apoyo en el Banco de Ojos y al Ing. Rafael Baruch Hernández Guerra por su apoyo en la estadística.

\section{BIBLIOGRAFÍA}

1. Villa C, Santodomingo J. La córnea. Parte I. Estructura, función y anatomía. Gaceta óptica: Órgano Oficial del Colegio Nacional de Ópticos-Optometristas de España. 2010; 454: 14-18.
2. Kanski JJ. Oftalmología clínica. 6a ed. Barcelona: Elsevier, España S.L. 2009, p. 33.

3. González PM, Neri VR, Quintero CR. El trasplante de córnea en México. Antecedentes históricos. Revista Mexicana de Oftalmología, 2020; 86 (4): 187-190.

4. Navarro MC, Calatayud PM. Obtención de tejido corneal para queratoplastia. Archivos de la Sociedad Española de Oftalmología. 2016; 91: 491-500.

5. Vázquez A, Tello R, Gaxiola T, Ruelas R, Gutiérrez I, Paz P. Queratoplastia penetrante. Centro Nacional de Excelencia Tecnológica en Salud. 2011, pp. 2-48.

6. Committee for the Cornea Donor Study Research Group, Sugar A, Robin LG, Kollman C, Raghinaru D, Dontchev M, Dontchev $\mathrm{M}$ et al. Factors associated with corneal graft survival in the cornea donor study. JAMA Ophthalmol. 2015; 133 (3): 246-254.

7. Contreras CR, Anaya PE, Gallegos VA, Villarreal MJ. Densidad y morfología de células del endotelio corneal en adultos jóvenes del norte de México. Rev Mex Oftalmol. 2014; 88 (3): 99-103.

8. Krohn J, Høvding G. The influence of donor age and cause of death on corneal endothelial cell density. Acta Ophthalmol Scand. 2005; 83 (6): 746-750.

9. Beuschel, Hofmann T, Messerli J. Is die Abnahme der HornhautEndothelzellzahl mit dem Alter wirklich linear? /Is the Decrease in Corneal Endothelial Cell Density in Relation to Age Linear? Klin Monb Augenheilkd. 2015; 232: 375-379.

10. Molina RD, Gómez A. Evaluación por décadas de edad del comportamiento de las células endoteliales corneales en población mexicana. Rev Mex Oftalmol. 2005; 79 (2): 93-100.

11. Casillas-Chavarin N, Alvarado-Castillo B, Ramirez-Padilla M, Navarro-Solares A, Gonzalez-Gomez HS. Prevalencia de queratitis por exposición en pacientes en estado crítico. Revista Mexicana de Oftalmología. 2017; 91 (2): 62-66.

12. Solano A, Diaz JF, Granados M, Rodríguez F. Prevención y manejo de queratopatía por exposición en pacientes de cuidado intensivo. Revisión de la literatura. Repertorio de Medicina y Cirugía. 2016; 25: 146-150.

13. Centro Nacional de Trasplantes. Reporte anual 2019 de Donación y Trasplantes en México. Sistema Informático del Registro Nacional de Trasplantes. 2020.

14. Instituto Mexicano del Seguro Social. Queratopatía Bullosa Secundaria a Cirugía de Catarata, División de Excelencia Clínica 
Coordinación de Unidades Médicas de Alta Especialidad, 2011, pp. 1-40.

15. Guerra AM, Pérez PZ, Taimí CC, Ariocha CA, Castillo PA, Casas AX. Morfología y morfometría del endotelio corneal. Revista Cubana de Oftalmología. 2015; 28 (3): 366-373.

16. Organización Nacional de Trasplantes, Plan Nacional de Córneas, Ministerio de Sanidad, Servicios Sociales e Igualdad, 2016, pp. 1-39.
17. Verdiguel SK, Carrasco QA, López MP, Ortiz LR. Calidad de tejido corneal procurado por personal médico no oftalmólogo capacitado. Rev Med Inst Mex Seguro Soc. 2016; 54 (6): 688-695.

\section{Correspondencia:}

Dra. Marcela Tejeda-Mondragón E-mail: dratejedaoft@hotmail.com 